\title{
PENGARUH KEJUTAN BUDAYA ASING (CULTURE SHOCK) TERHADAP PERILAKU DAN KINERJA KARYAWAN BANK WOORI SAUDARA WILAYAH BOGOR
}

\author{
THE EFFECT OF CULTURE SHOCK TOWARD EMPLOYEE BEHAVIOR AND EMPLOYEE PERFORMANCE \\ AT BANK WOORI SAUDARA BOGOR BRANCH
}

\author{
Dian Putri Indriani*), Aida Vitayala Hubeis ${ }^{* *}$, dan Sadikin Kuswanto*) \\ ${ }^{*}$ Sekolah Bisnis, IPB University \\ Jl. Pajajaran Bogor 16151, Indonesia \\ ${ }^{* *}$ Departemen Sains Komunikasi dan Pengembangan Masyarakat, Fakultas Ekonomi Manusia, IPB University \\ Jl. Darmaga, Kampus IPB Darmaga, Bogor 16680, Indonesia
}

\begin{abstract}
Bank Woori Saudara (BWS) is a merger between PT Bank Himpunan Saudara and Bank Woori Indonesia which brought togather two different cultures that are Indonesian culture and South Korean culture. Cultural changes at BWS require employees to adapt to new culture. Ineffective adaptation lead to many employees chosing to resign from $B W S$. The purpose of this study was to analyze the influence of culture shock on employee behavior and employee performance at BWS Bogor. The type of this study is explanatory research with survey method using primary data. The research data were obtained through questionnaire using a likert measurement scale with score of 1 to 5 and then distributed to 37 respondents who had been selected using non-probability sampling techniques that are classified as census. And secondary data through the method of observation, interview and literature study. The research was conducted using descriptive analysis for characteristcs respondens and path coefficient between the research variables using SmartPLS 3.0 software. The results showed that there was a significant influence between culture shock on employee behavior and employee performance positively. This is means that employees behavior to resign from BWS are influenced by affective domain, which is lack of appreciation that given by BWS. And later found that employee behavior does not affect employee performance.
\end{abstract}

Keywords: culture shock, employee behavior, employee performance, individual characteristic, PLS

\begin{abstract}
Abstrak: Bank Woori Saudara (BWS) merupakan penggabungan antara Bank Himpunan Saudara dengan Bank Woori Indonesia sehingga menggabungkan dua budaya yang berbeda yaitu budaya Indonesia dengan budaya Korea Selatan. Perubahan budaya di BWS menuntut karyawan untuk beradaptasi dengan budaya baru. Adaptasi budaya yang tidak efektif memicu banyaknya karyawan memilih untuk berhenti bekerja. Tujuan dari penelitian ini adalah untuk menganalisis pengaruh kejutan budaya terhadap perilaku karyawan dan kinerja karyawan di BWS Bogor. Jenis penelitian ini adalah penelitian eksplanatori dengan metode survey berupa data primer yaitu kuisioner dengan skala pengukuran likert (1-5) yang didistribusikan kepada 37 responden yang dipilih menggunakan teknik pengambilan sampel non-probabilitas tergolong pada sensus. Dan data sekunder berupa metode observasi, wawancara dan studi literatur. Penelitian dilakukan dengan analisis deskriptif terhadap karakteristik responden dan koefisien jalur antar peubah penelitian dengan menggunakan perangkat lunak SmartPLS 3.0. Hasil penelitian menunjukkan bahwa ada pengaruh yang signifikan antara kejutan budaya terhadap perilaku karyawan dan kinerja karyawan secara positif. Artinya perilaku karyawan untuk berhenti bekerja dipengaruhi oleh kawasan afektif yaitu kurangnya penghargaan yang diberikan oleh BWS. Dan kemudian ditemukan bahwa perilaku karyawan tidak mempengaruhi kinerja karyawan.
\end{abstract}

Kata kunci: kejutan budaya, perilaku karyawan, kinerja karyawan, karakteristik individu, PLS

\footnotetext{
${ }^{1}$ Alamat Korespondensi:

Email: dee18_caem@yahoo.co.id
} 


\section{PENDAHULUAN}

Indonesia sampai saat ini masih menjadi salah satu negara pilihan tujuan ekspansi bisnis perusahaanperusahaan multinasional untuk mengembangkan bisnisnya dengan membuka kantor cabang perwakilan maupun melakukan merger atau penggabungan usaha dengan perusahaan lokal di Indonesia. Penggabungan usaha tersebut akan menggabungkan dua budaya yang berbeda yaitu budaya asli Indonesia dengan budaya asing dari negara lain, sebagai contoh perusahaan tersebut akan mengirim karyawannya untuk penugasan internasional lintas budaya yang kita kenal dengan istilah ekspatriat. Ekspatriat adalah karyawan yang dikirim oleh sebuah perusahaan di suatu negara untuk mengelola operasi di negara yang berbeda (Noe et al. 2010).

Ada konsekuensi yang dihadapi oleh ekspatriat dalam penugasan internasional lintas budaya antara lain perbedaan budaya, bahasa, keyakinan, norma, tradisi dankondisialam. Penelitan Andreason (2003) expatriate adjustment to foreign assignments mengidentifikasi tiga dimensi penyesuaian ekspatriat yaitu penyesuaian untuk bekerja, penyesuaian untuk interaksi dengan orang-orang di negara asing dan penyesuaian umum terhadap budaya dan kondisi kehidupan. Sehingga mempelajari dan mengerti tentang budaya ditempat penugasan dapat menciptakan lingkungan yang kondusif dan nyaman bagi semua pihak menjadi tugas wajib ekspatriat. Diketahui bahwa mempelajari tentang budaya tuan rumah dan konsepnya mampu mengurangi perasaan negatif (Oberg, 1958; Hisam, 1996; Eull, 2005; Mansour and Wood, 2010; Feng, 2015; Morgan, 2015; Rodriguez, 2017).

PT Bank Woori Saudara Indonesia 1906 Tbk (BWS) merupakan bank hasil penggabungan antara PT Bank Himpunan Saudara Indonesia 1906 Tbk yang tergabung dalam Medco group dengan Bank Woori Indonesia yang merupakan bagian dari Woori Korea group di tahun 2015. Hasil penggabungan tersebut menyatukan budaya asli Indonesia dengan budaya Korea Selatan. Penggabungan yang terjadi menyebabkan adanya perubahan tidak hanya pada komposisi kepemilikan saham, tetapi juga logo, visi dan misi serta budaya dalam lingkungan kerja perusahaan. Joseph dan Francis (2015) menyatakan bahwa keberhasilan organisasi bergantung pada tercapainya kesesuaian yang baik antara strategi, struktur dan budaya. Budaya kerja yang baik menciptakan lingkungan kerja yang baik hingga nantinya akan membentuk sumber daya manusia yang baik juga.

Dari perspektif teoritis, kejutan budaya merupakan stres yang disebabkan oleh perbedaan ekspektasi perilaku dan ketidakpastian yang harus dihadapi oleh individu (Black dan Gregersen, 1991; Shi dan Wang, 2014). Pada saat individu mengalami kejutan budaya, maka proses tersebut melibatkan aspek kognitif, afektif dan psikomotor yang ada dalam dirinya. Aspek kognitif bagaimana individu menginterpretasikan orang lain, institusi mau pun peristiwa-peristiwa dilingkungan budaya baru. Aspek afektif yaitu bagaimana keadaan emosional yang muncul dalam menghadapi budaya baru meliputi perasaan bingung, curiga dan ingin berada dilingkungan yang lebih nyaman. Aspek psikomotorik berhubungan dengan prosespengembangankemampuan sosial saat berinteraksi dalam lingkungan baru.

BWS wilayah Bogor adalah BWS ex-bank Saudara dengan bisnis inti perusahaan adalah pelayanan pembayaran pensiun untuk para pensiunan TASPEN, ASABRI dan DAPEN lainnya dengan budaya Sunda. Budaya Sunda dikenal dengan budaya yang menjunjung tinggi sopan santun dengan karakter masyarakatnya yang periang, ramah-tamah, murah senyum, lemah lembut dan sangat menghormati orang tua (Adi, 2018). Setelah penggabungan di tahun 2015, bisnis inti perusahaan bertambah yaitu bisnis korporasi seiring dengan perubahan manajemen perusahaan dan munculnya nasabah asing Korea Selatan sehingga secara perlahan budaya Korea Selatan masuk ke BWS wilayah Bogor. Budaya Korea Selatan dikenal dengan bekerja keras, cepat dan gesit, ambisius, fokus dengan karakter masyarakatnya yang rajin, pekerja yang disiplin, patuh pada senior dan atasan karena menganut prinsip senioritas, tekun dalam pekerjaan, sebelum pekerjaan selesai tidak pulang bahkan bekerja sampai malam, memiliki temperamen yang tinggi, marah bila ada masalah namun tidak pendendam (Mochklas, 2017; Mochklas dan Fatihudin, 2017). Budaya kerja Korea Selatan lebih menekankan disiplin pada pencapaian target secara fleksibel dan tidak toleran. Proses penyelesaian pekerjaan tidak terlalu dikhawatirkan selama target perusahaan tercapai ((Mayangsari et al. 2014).

Pada awalnya karyawan BWS melayani nasabah pensiunan pribumi dengan ritme kerja yang tidak membutuhkan kecepatan, perlahan namun pasti karena nasabah pensiunan adalah orang tua yang harus 
dihormati dan dilayani dengan lemah lembut dan murah senyum. Namun setelah penggabungan karyawan mulai berhadapan dengan nasabah Korea Selatan yang tidak bisa berbahasa Indonesia dengan baik maupun bahasa Inggris, berbicara dengan nada tinggi seperti berteriak, tidak mau menunggu dalam antrian dan selalu menjadikan diri mereka sebagai nasabah VIP yang harus lebih dahulu dilayani. Hal ini menjadi hambatan dalam berkomunikasi, karyawan sulit untuk memahami apa yang diinginkan oleh nasabah tersebut sehingga berpengaruh pada perilaku karyawan.

Munculnya hambatan dalam berkomunikasi dengan nasabah memengaruhi kinerja karyawan diantaranya kesanggupan karyawan mengerjakan pekerjaan tepat waktu dan pekerjaan dilakukan dengan benar tanpa melakukan kesalahan. Begitu juga dengan adanya perbedaan keyakinan, masyarakat Indonesia mayoritas beragama muslim sedangkan masyarakat Korea Selatan mayoritas beragamanon muslim sehinggaketidaktahuan mereka terhadap agama Islam menimbulkan hambatan dalam berinteraksi sehingga berpengaruh terhadap kinerja karyawan, membuat kualitas layanan di BWS tidak bagus karena mereka harus menunggu karyawan yang sedang beribadah, hal tersebut sangat bertentangan dengan budaya mereka yang serba ingin cepat (pali pali). Gustari (2013) menyebutkan bahwa perbedaan budaya organisasi menjadi kendala utama dalam kesuksesan proses penggabungan. Perubahan budaya organisasi berpengaruh signifikan terhadap kinerja karyawan dengan arah positif. Semakin besar perubahan budaya organisasi akan berdampak pada semakin baiknya kinerja karyawan. Ahidin dan Mutaqin (2014) menyebutkan bahwa banyak faktor yang dapat memengaruhi kinerja karyawan salah satunya adalah faktor kontekstual (situasional) meliputi budaya organisasi, tekanan dan perubahan lingkungan eksternal dan internal.

Ketidaksiapan karyawan dalam menerima budaya baru yang datang menyebabkan munculnya hambatan dalam menghadapi perbedaan sehingga diperlukan proses adaptasi dalam budaya baru. Adaptabilitas budaya organisasi dapat memengaruhi karyawan untuk berkomitmen (Wulandary et al. 2017). Adaptasi yang tidak efektif akan menyebabkan terjadinya kejutan budaya. Kejutan budaya dalam bahasa Indonesia diartikan sebagai goncangan budaya merupakan istilah psikologis yang menggambarkan keadaan dan perasaan seseorang menghadapi kondisi lingkungan sosial budaya yang berbeda (Sulaeman 1995). Penelitian ini dilakukan untuk menganalisis pengaruh kejutan budaya yang muncul akibat adanya perbedaan budaya terhadap perilaku dan kinerja karyawan. Proses penyesuaian terhadap budaya Korea Selatan yang tidak terlaksana dengan baik di BWS wilayah Bogor memengaruhi perilaku dan kinerja karyawan yang menyebabkan banyaknya karyawan memilih untuk berhenti bekerja dilihat dari jumlah karyawan tetap di BWS terus menurun sejak penggabungan di tahun 2015. Sehingga perlu untuk merumuskan program-program pendukung untuk mengatasi kejutan budaya tersebut.

\section{METODE PENELITIAN}

Penelitian dilakukan di BWS wilayah Bogor karena BWS wilayah bogor merupakan BWS eks-bank Saudara sehingga lebih terlihat perubahan budaya yang muncul setelah penggabungan. BWS Bogor terdiri dari BWS KC Bogor, BWS KCP Depok, BWS KCP Cibinong, BWS KCP Leuwiliang, BWS KCP Parung, BWS Kantor Kas Ciawi dan BWS Kantor Kas Pasar Anyar. Penelitian dilakukan sejak April 2019 sampai dengan Desember 2019. Jenis penelitian adalah penelitian eksplanatori dengan metode survey, menggunakan data primer berupa kuisioner yang diukur berdasarkan skala likert dengan skor 1 sampai 5 (Tabel 1) dan data sekunder berupa observasi dan wawancara tidak terstruktur terhadap general manajer, studi literatur seperti jurnal, tesis, disertasi, artikel ilmiah, dan laporan tahunan sumber daya manusia BWS.

Sampel penelitian adalah karyawan BWS Bogor yang dipilih menggunakan teknik non probability sampling yang tergolong sensus. Dari total karyawan BWS Bogor yang berjumlah sebanyak 53 orang, yang bisa dijadikan sampel penelitian sebanyak 37 orang terdiri dari pemimpin cabang (2 orang), manajer/supervisor (10 orang) dan senior staff (25 orang). Prosedur pengolahan dan analisis data yang dilakukan adalah analisis deskriptif yang dilakukan terhadap karakteristik responden dan seluruh peubah penelitian sehingga terlihat perbedaannya terhadap peubah-peubah penelitian. Analisis deskriptif dengan menggunakan excel antara lain mean, standar deviasi, interval, sum, maksimum dan minimum. Kemudian uji beda dilakukan dengan menggunakan independensi t-tes dan non parametrik menggunakan uji mannwhitney dan uji kruskal wallis. 
Tabel 1. Skala likert persepsi responden

\begin{tabular}{lc}
\hline Persepsi Responden & Skor Skala Likert \\
\hline STS (Sangat Tidak Setuju) & 1 \\
TS (Tidak Setuju) & 2 \\
N (Netral) & 3 \\
S (Setuju) & 4 \\
SS (Sangat Setuju) & 5 \\
\hline
\end{tabular}

Partial Least Square (PLS) digunakan untuk mengestimasi model koefisien jalur kontruk laten nya terhadap dimensi penelitian yang diberikan. PLS dilakukan dilakukan dengan dua model yaitu model pengukuran (outer model) untuk uji validitas dan reliabilitas seluruh dimensi dan indikator peubahpeubah penelitian dengan menggunakan Confirmatory Factor Analysis (CFA) metode second order. Indikator dikatakan valid dengan melihat convergent validity dengan nilai loading factor $>0,5$ dan nilai Average Variance Extracted (AVE) dengan nilai lebih dari 0,5. Pengujian discriminant validity pada second order menggunakankriteriaFornell-Larckeryangmenyatakan bahwa jika nilai akar AVE lebih tinggi dibandingkan dengan korelasi antar konstruk yang lain maka konstruk memiliki tingkat dicriminant validity yang baik. Uji reliabilitas diukur dengan nilai cronbach's alpha dan composite reliability $(C P)$, dikatakan reliabel jika memiliki nilai lebih dari 0,07. Model struktural (inner model) dari PLS dilakukan dengan estimasi full model struktural dengan menggunakan laten variabel score untuk melihat nilai koefisien standardized (path) antar peubah dan untuk mengetahui signifikansi hubungan antar peubah digunakan metode bootstraping.

Penggabungan usaha menyebabkan adanya penambahan bisnis inti baru yang membawa serta budaya baru sehingga dibutuhkan proses adaptasi oleh karyawan BWS Bogor. Budaya Korea Selatan yang sangat berbeda dengan budaya Sunda menimbulkan kecemasan karyawan bagaimana untuk bersikap dan berperilaku dalam lingkungan yang baru. Perilaku karyawan yang memutuskan berhenti bekerja setelah penggabungan usaha sejak 2015 dipicu oleh adaptasi yang tidak efektif. Adanya ketidaksesuaian antara beban kerja yang bertambah dengan penghargaan/benefit yang diharapkan oleh karyawan. Dan tidak dapat dipungkiri bahwa budaya baru membawa pengetahuan dan keterampilan baru bagi karyawan yang nantinya akan berdampak pada peningkatan kinerja karyawan. Perlu teliti juga bahwa apakah perilaku karyawan berhenti bekerja juga dipengaruhi oleh tingkat kemampuan karyawan dalam menerima pengetahuan baru. Oleh karena itu, diajukan hipotesis pada penelitian sebagai berikut:

H1 : Kejutan budaya berpengaruh terhadap perilaku karyawan

H2 : Kejutan budaya berpengaruh terhadap tingkat kinerja karyawan

H3 : Perilaku karyawan berpengaruh terhadap tingkat kinerja karyawan

Kerangka penelitian pada Gambar 1 memerlihatkan bahwa penelitian dimulai dengan mengelompokkan responden yaitu karyawan BWS Bogor berdasarkan kriteria yang sudah ditentukan. Analisis diawali dengan memberikan kuisioner kepada responden untuk mengetahui persepsi mereka terhadap setiap peubah penelitian yang telah diberikan dimensi yaitu kejutan budaya, perilaku karyawan dan kinerja karyawan dalam kondisi lingkungan kerja yang baru. Dimensi kejutan budaya adalah tahapan bulan madu, tahapan kejutan budaya, tahapan pemulihan dan tahapan adaptasi. Dimensi perilaku karyawan adalah aspek kognitif, aspek afektif dan aspek psikomotirik. Sedangkan dimensi kinerja karyawan adalah kualitas, kuantitas, ketepatan waktu, efektifitas, kemandirian. Selanjutnya hasil analisis dapat menjadi informasi bagi manajemen untuk merumuskan program pendukung dalam mengatasi permasalahan yang ada.

\section{HASIL}

\section{Analisis Deskriptif - Karakteristik Individu}

\section{Jøgis Kelamin}

Tabel 2 memerlihatkan kejutan budaya yang dialami karyawan perempuan lebih tinggi dibandingkan dengan karyawan laki-laki, dan memang ditemukan bahwa lebih banyak karyawan perempuan di BWS yang memilih berhenti bekerja dan memutuskan untuk menjadi ibu rumah tangga. Hal tersebut disampaikan oleh Melly (2020) yang menyebutkan bahwa "keputusan untuk berhenti bekerja di BWS Bogor didominasi oleh karyawan perempuan dengan alasan ingin mengurus keluarga". Namun, tidak ditemukan adanya perbedaan perilaku dan kinerja antara karyawan laki-laki dan perempuan. 


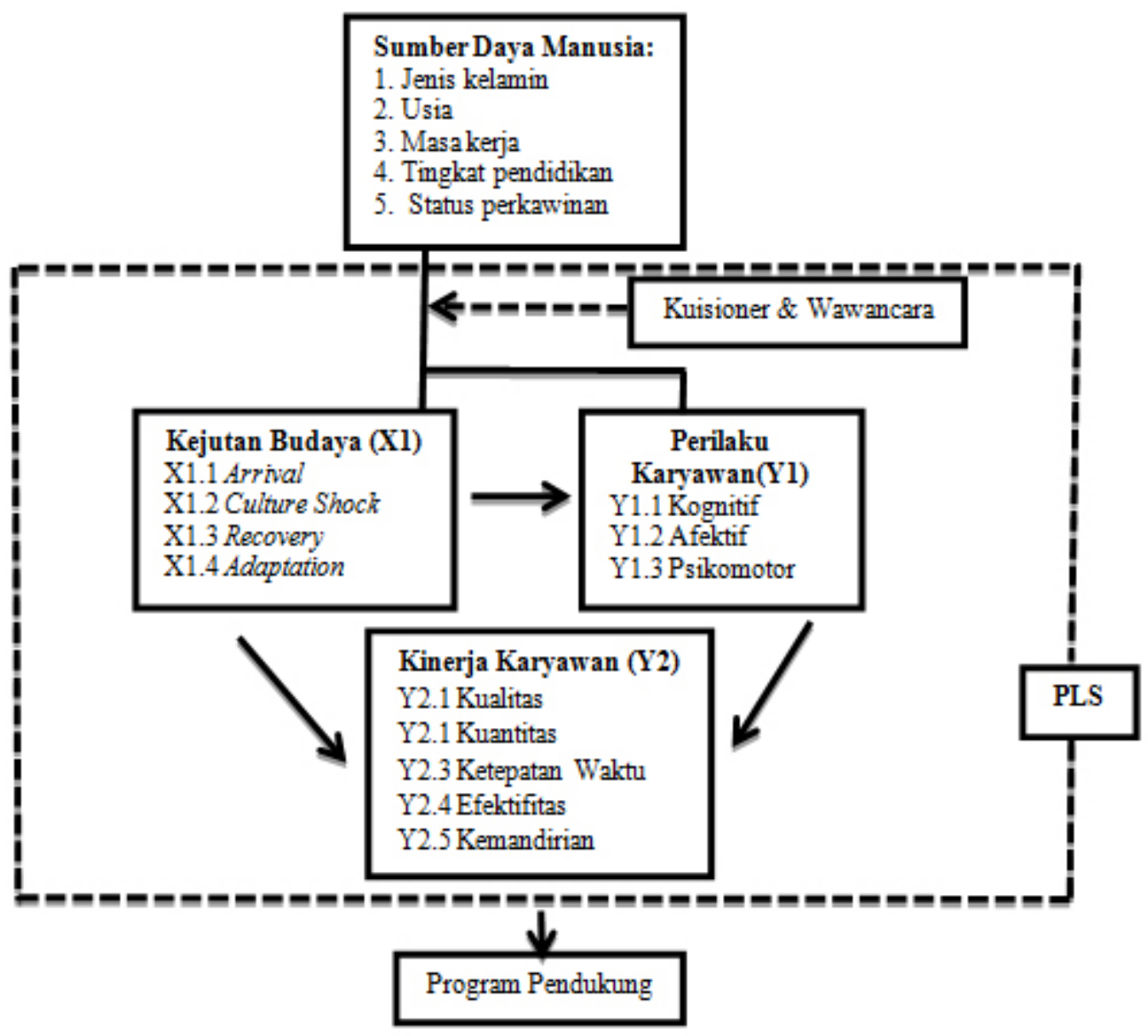

Gambar 2. Kerangka pemikiran penelitian

Tabel 2. Pengaruh jenis kelamin terhadap peubah penelitian

\begin{tabular}{|c|c|c|c|c|c|c|}
\hline \multirow{2}{*}{ Peubah } & \multicolumn{2}{|c|}{ Laki-laki } & \multicolumn{2}{|c|}{ Perempuan } & \multirow{2}{*}{ P-value } & \multirow{2}{*}{ Kesimpulan } \\
\hline & Rata-rata & Std.Dev & Rata-rata & Std.Dev & & \\
\hline Kejutan Budaya & 3,32 & 0,39 & 3,59 & 0,34 & 0,033 & Berbeda \\
\hline Perilaku Karyawan & 3,36 & 0,38 & 3,46 & 0,39 & 0,428 & Tidak berbeda \\
\hline Kinerja Karyawan & 3,73 & 0,30 & 3,90 & 0,30 & $0,065^{*}$ & Tidak berbeda \\
\hline
\end{tabular}

Keterangan : * adalah hasil pengujian tes non-parametik dengan uji Mann Whitney, berbeda jika $\mathrm{p}$ value $<0,05$

\section{Usia}

Dari hasil uji perbedaan yang dilakukan pada karakteristik usia pada Tabel 3, diketahui bahwa tidak terdapat perbedaan antara rentang usia dengan kejutan budaya dan perilaku karyawan. Perbedaan terlihat pada peubah kinerja dengan nilai $p$-value $<0,05$ artinya usia memengaruhi kinerja karyawan. Dilihat dari Tabel 3, nilai mean karyawan dengan rentang usia 23-33 tahun memiliki kinerja yang lebih baik daripada karyawan dengan rentang usia 34-44 tahun.

\section{Masa Kerja}

Berdasarkan Tabel 4 hasil uji perbedaan diketahui nilai $p$-value untuk semua peubah penelitian lebih besar dari
0,05 . Artinya tidak ada perbedaan antara karakteristik masa kerja dengan peubah-peubah penelitian. Hal ini disebabkan karena masa kerja yg digunakan sudah dikriteriakan yaitu karyawan yang berstatus karyawan tetap sebelum penggabungan dilakukan sampai dengan saat ini.

\section{Tingkat Pendidikan}

Hasil uji perbedaan yang ditampilkan dalam Tabel 5 memerlihatkan nilai $p$-value untuk semua peubah penelitian lebih besar dari 0,05. Artinya tidak ada perbedaan antara kategori tingkat pendidikan dengan semua peubah penelitian. Hal ini disebabkan karena tingkat pendidikan di BWS wilayah Bogor mayoritas hampir sama yaitu pada tingkat sarjana. 
Tabel 3, Pengaruh usia terhadap peubah penelitian

\begin{tabular}{lccccc}
\hline Peubah & Usia & Mean & Std,Deviasi & P-value & Kesimpulan \\
\hline Kejutan Budaya & $23-33$ tahun & 3,67 & 0,33 & $0,095^{*}$ & Tidak berbeda \\
& $34-44$ tahun & 3,39 & 0,39 & & \\
& $\geq 45$ tahun & 3,00 & - & & \\
Perilaku Karyawan & $23-33$ tahun & 3,57 & 0,46 & 0,287 & Tidak berbeda \\
& $34-44$ tahun & 3,34 & 0,35 & & \\
Kinerja Karyawan & $\geq 45$ tahun & 3,47 & - & & \\
& $23-33$ tahun & 3,95 & 0,28 & $0,037^{*}$ & Berbeda \\
& $34-44$ tahun & 3,79 & 0,28 & & \\
\hline
\end{tabular}

Keterangan : * adalah hasil pengujian tes non-parametrik dengan uji Kruskal Wallis, berbeda jika p-value $<0,05(\alpha)$

Tabel 4. Pengaruh masa kerja terhadap peubah penelitian

\begin{tabular}{lccccc}
\hline Peubah & Masa Kerja & Mean & Std.Deviasi & P-value & Kesimpulan \\
\hline Kejutan Budaya & $6-10$ tahun & 3,41 & 0,41 & 0,974 & Tidak berbeda \\
& $11-15$ tahun & 3,53 & 0,36 & & \\
Perilaku Karyawan & $\geq 15$ tahun & 3,65 & 0,18 & & \\
& 6-10 tahun & 3,42 & 0,38 & 0,557 & Tidak berbeda \\
& $11-15$ tahun & 3,39 & 0,43 & & \\
Kinerja Karyawan & $\geq 15$ tahun & 3,38 & 0,29 & & Tidak berbeda \\
& 6-10 tahun & 3,80 & 0,28 & 0,855 & \\
\hline
\end{tabular}

Keterangan : berbeda jika p-value $<0,05(\alpha)$

Tabel 5. Pengaruh tingkat pendidikan terhadap peubah penelitian

\begin{tabular}{lccccc}
\hline Peubah & $\begin{array}{c}\text { Tingkat } \\
\text { Pendidikan }\end{array}$ & Mean & Std.Deviasi & P-value & Kesimpulan \\
\hline Kejutan Budaya & D3 & 3,32 & 0,29 & 0,164 & Tidak berbeda \\
& S1 & 3,50 & 0,38 & & \\
Perilaku Karyawan & S2 & 3,09 & 0,61 & & \\
& D3 & 3,16 & 0,07 & 0,268 & Tidak berbeda \\
Kinerja Karyawan & S1 & 3,46 & 0,39 & & \\
& S2 & 3,09 & 0,37 & & Tidak berbeda \\
& D3 & 3,73 & 0,17 & 0,581 & \\
\hline
\end{tabular}

Keterangan : berbeda jika p-value $<0,05(\alpha)$

\section{Status Penikahan}

Pernikahan memunculkan tingkat tanggung jawab yang tinggi sehingga suatu pekerjaan tetap akan menjadi lebih berharga bagi karyawan yang sudah menikah dibandingkan dengan rekan kerja yang belum menikah. Dari hasil uji perbedaan pada Tabel 6 diketahui bahwa tidak ditemukan respon yang berbeda antara karyawan yang sudah menikah dengan yang belum menikah terhadap semua peubah penelitian. Hal ini dikarenakan hampir seluruh karyawan BWS wilayah Bogor berstatus menikah.

\section{Analisis Deskriptif - Peubah Penelitian}

Perhitungan tanggapan responden sebagai berikut:

1. Nilai indeks maksimum sama dengan skala tertinggi dengan nilai 5 
2. Nilai indeks minimum sama dengan skala terendah dengan nilai1

3. Jarak interval

$=[$ nilai maksimum-nilai minimum $]: 5$

$=(5-1): 5=0,8$

Responden memberikan nilai rata-rata tanggapan terhadap peubah penelitian sesuai kuisioner penelitian dalam kategori baik dengan indeks rata-rata berkisar antara 3,41-4,20 disajikan dalam Tabel 7. Dari hasil analisis deskriptif pada Tabel 8 diketahui bahawa peubah kinerja karyawan diberikan nilai paling tinggi sebesar 3,81 artinya karyawan merespon lebih baik pada peubah penelitian ini. Selanjutnya peubah kejutan budaya diberikan nilai 3.46 lebih kecil dibandingkan peubah kinerja karyawan artinya karyawan mengalami kejutan budaya sebagai dampak dari perubahan budaya di BWS wilayah Bogor, bahkan 4 tahun setelah penggabungan karyawan masih berada pada tahap pemulihan yaitu mengerti lingkungan kerjanya, memahami diri sendiri dan berkurangnya kecemasan dalam bekerja. Peubah perilaku karyawan dinilai 3,41 paling rendah dari semua peubah penelitian artinya dampak paling besar dari perubahan budaya dalam lingkungan kerja berpengaruh pada perubahan perilaku karyawan.

\section{Analisis Partial Least Square (PLS)- Model Pengukuran (outer model)}

Outermodelataupengukuranbagian luarmendefinisikan bagaimana setiap indikator berhubungan dengan peubah latennya. Penelitian ini menggunakan peubah kejutan budaya (X1) yang diukur dengan empat dimensi yang terdiri dari dua puluh tiga indikator. Selanjutnya peubah perilaku karyawan (Y1) yang diukur dengan tiga dimensi dan terdiri dari tujuh belas indikator serta peubah kinerja karyawan (Y2) yang diukur dengan lima dimensi yang terdiri dari dua puluh enam indikator. Diperoleh hasil bahwa semua peubah dan indikator valid untuk digunakan dalam penelitian ini yang ditampilkan pada Tabel 9.

\section{Inner Model (Model Struktural)}

Penelitian model struktural terkait dengan tiga hipotesis penelitian yang mengisyaratkan hubungan kausalitas diantara peubah-peubah laten. Etimasi full model struktural menghasilkan koefisien standardized (path) antar peubah dengan nilai positif pada Gambar 2. Dan signifikansi hubungan antar peubah digunakan metode bootstraping pada Gambar 3.

Tabel 6. Pengaruh status pernikahan terhadap peubah peubah penelitian

\begin{tabular}{|c|c|c|c|c|c|}
\hline Peubah & $\begin{array}{c}\text { Status } \\
\text { Pernikahan }\end{array}$ & Mean & Std.Deviasi & P-value & Kesimpulan \\
\hline \multirow[t]{2}{*}{ Kejutan Budaya } & Menikah & 3,46 & 0,40 & 0,216 & Tidak berbeda \\
\hline & Belum Menikah & 3,39 & 0,18 & & \\
\hline \multirow[t]{2}{*}{ Perilaku Karyawan } & Menikah & 3,42 & 0,39 & 0,676 & Tidak berbeda \\
\hline & Belum Menikah & 3,21 & 0,04 & & \\
\hline \multirow[t]{2}{*}{ Kinerja Karyawan } & Menikah & 3,82 & 0,31 & 0,33 & Tidak berbeda \\
\hline & Belum Menikah & 3,62 & 0,00 & & \\
\hline
\end{tabular}

Keterangan : berbeda jika p-value $<0.05(\alpha)$

Tabel 7. Kategori nilai tanggapan responden

\begin{tabular}{lc}
\hline Indeks Rata-rata & Kategori \\
\hline $4,21-5,00$ & Sangat Baik \\
$3,41-4,20$ & Baik \\
$2,61-3,40$ & Cukup \\
$1,81-2,60$ & Kurang Baik \\
$1,00-1,80$ & Tidak Baik \\
\hline
\end{tabular}

Tabel 8. Deskriptif seluruh peubah penelitian

\begin{tabular}{lc}
\hline Peubah penelitian & Skor rata-rata \\
\hline Kejutan budaya (X1) & 3,46 \\
Perilaku karyawan (Y1) & 3,41 \\
Kinerja Karyawan (Y2) & 3,81 \\
\hline
\end{tabular}


Tabel 9. Hasil uji validitas dan reliabilitas peubah penelitian

\begin{tabular}{|c|c|c|c|c|c|c|}
\hline Peubah laten & Dimensi & $\begin{array}{l}\text { Nilai loading } \\
\text { factor }\end{array}$ & AVE & $\begin{array}{c}\text { Cronbach's } \\
\text { alpha }\end{array}$ & CR & Simpulan \\
\hline \multirow[t]{4}{*}{ Kejutan Budaya (X1) } & Honeymoon & 0,864 & 0,660 & 0,836 & 0,879 & Valid \\
\hline & Culture Shock & 0,685 & & 0,769 & 0,867 & Valid \\
\hline & Recovery & 0,866 & & 0,848 & 0,898 & Valid \\
\hline & Adjustment & 0,820 & & 0,803 & 0,864 & Valid \\
\hline \multirow[t]{3}{*}{ Perilaku Karyawan (Y1) } & Kognitif & 0,826 & 0,713 & 0,829 & 0,887 & Valid \\
\hline & Afektif & 0,872 & & 0,861 & 0,900 & Valid \\
\hline & Psikomotor & 0,835 & & 0,835 & 0,890 & Valid \\
\hline \multirow[t]{5}{*}{ Kinerja Karyawan (Y2) } & Kualitas & 0,631 & 0,509 & 0,908 & 0,930 & Valid \\
\hline & Kuantitas & 0,604 & & 0,825 & 0,876 & Valid \\
\hline & Ketepatan Waktu & 0,844 & & 0,899 & 0,927 & Valid \\
\hline & Efektifitas & 0,639 & & 0,779 & 0,850 & Valid \\
\hline & Mandiri & 0,813 & & 0,800 & 0,870 & Valid \\
\hline
\end{tabular}

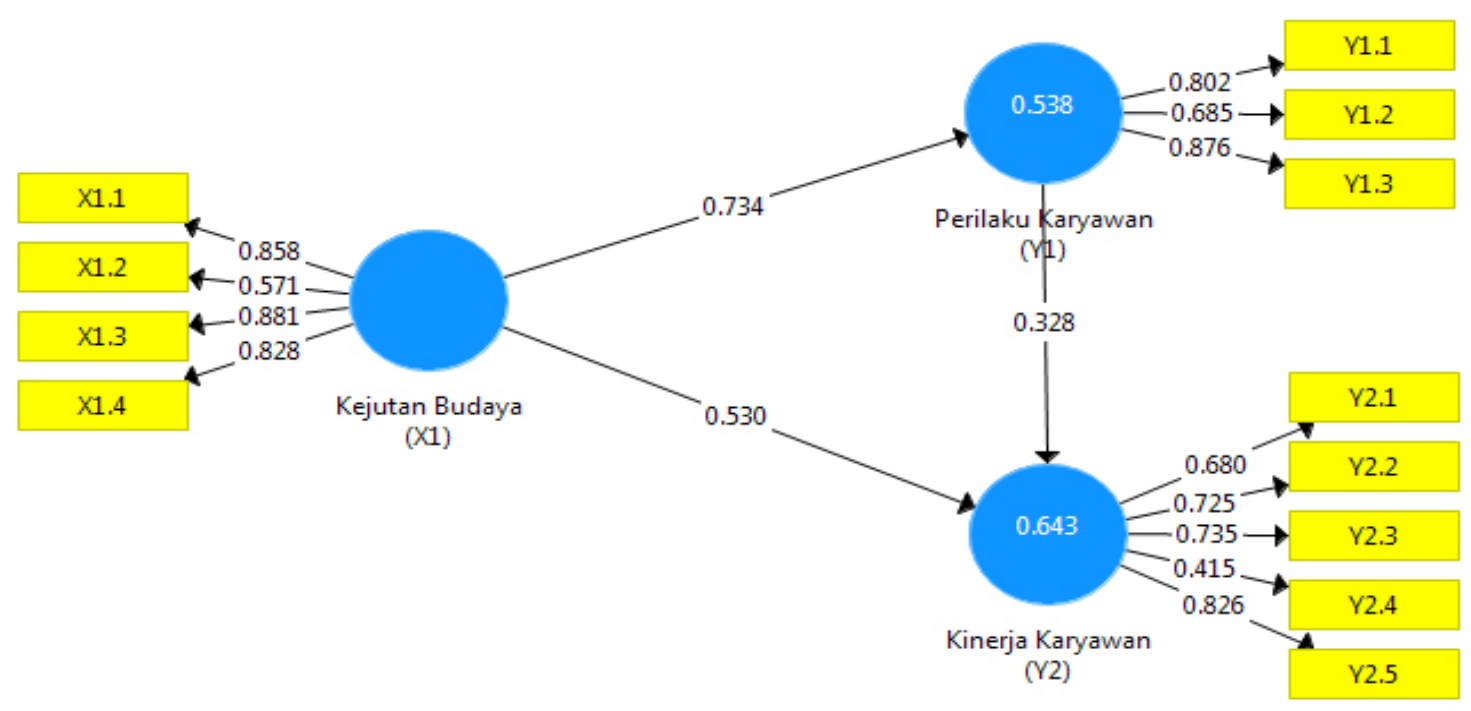

Gambar 2. Hasil estimasi full model struktural standardized

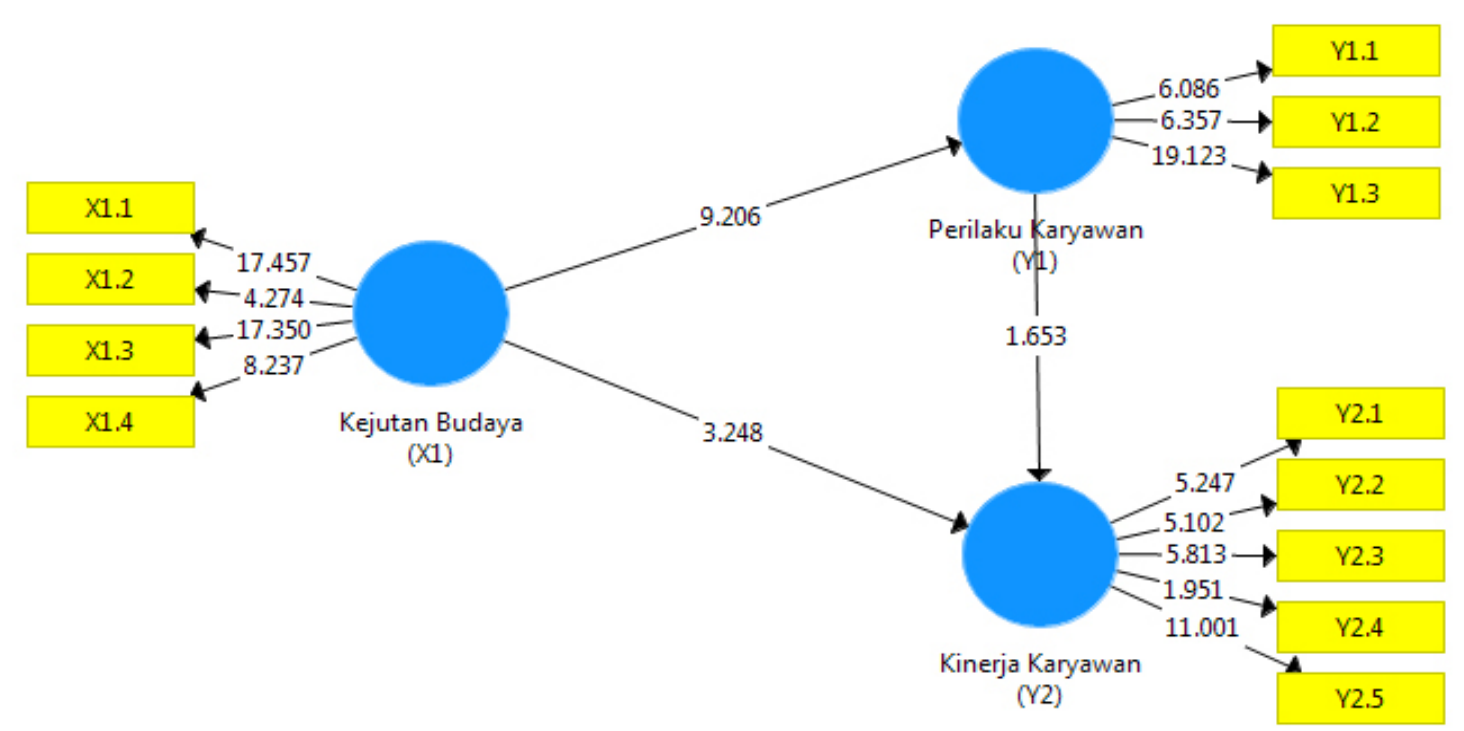

Gambar 3. Hasil full model struktural (bootstraping) 
Hasil estimasi model struktural hubungan antar peubah laten melalui uji koefisien jalur (path coeficient) pada Tabel 10. Apabila diilihat dari koefisien jalurnya, peubah kejutan budaya mempengaruhi kinerja karyawan secara dominan dengan koefisien jalur sebesar 0,530 (40,9\%). Dan baru kemudian perilaku karyawan terhadap kinerja karyawan dengan koefisien jalur sebesar 0,328 $(23,5 \%)$.

\section{Pengujian Hipotesis}

\section{Pengaruh Kejutan Budaya Terhadap Perilaku Karyawan}

Nilai koefisien jalur pada Tabel 10 memerlihatkan bahwa kejutan budaya berpengaruh signifikan terhadap perilaku karyawan dengan arah positif. Perubahan budaya terjadi mempengaruhi karyawan di kawasan afektif. Kawasan afektif merupakan segala sesuatu yang berkaitan dengan emosi seperti penghargaan, nilai, perasaan, semangat dan minat terhadap sesuatu hal. Setelah adanya perubahan budaya, karyawan merasa kurangnya penghargaan yang diberikan oleh perusahaan atas usaha mereka dalam mengerjakan pekerjaan dalam lingkungan budaya yang baru sehingga mempengaruhi perasaan dan menurunkan semangat serta minat dalam berkarir di BWS. Penelitian Nurwati (2012) dalam penelitiannya menemukan adanya pengaruh budaya organisasi terhadap perilaku karyawan dengan arah positif.

\section{Pengaruh kejutan budaya terhadap kinerja karyawan}

Nilai koefisien jalur pada Tabel 10 menunjukkan bahwa kejutan budaya yang muncul akibat perubahan budaya di BWS Bogor memengaruhi kinerja karyawan secara positif. Budaya Korea Selatan yang diterapkan dikantor mengharuskan karyawan meningkatkan keahlian dalam bekerja sehingga saat ini karyawan sudah bisa bekerja dengan ritme yang cepat, bisa melakukan pekerjaan diluar jobdesk yang ada dan bisa melakukan multitasking dalam bekerja. Memahami budaya baru yang sangat berbeda dengan budaya asli memerlukan usaha yang besar, sehingga nantinya berpengaruh terhadap peningkatan kemampuan individu dalam melakukan pekerjaan. Gustari (2013) ditemukan bahwa perubahan budaya organisasi berpengaruh signifikan terhadap kinerja karyawan dengan arah positif. Semakin besar perubahan budaya organisasi akan berdampak pada semakin baiknya kinerja karyawan.

\section{Pengaruh perilaku karyawan terhadap kinerja karyawan}

Interaksi timbal balik antara karyawan dengan nasabah Korea mempengaruhi kawasan afektif mereka. Perilaku karyawan yang memutuskan untuk berhenti bekerja dipengaruhi oleh kurangnya penghargaan yang diberikan oleh perusahaan terhadap usaha yang sudah dilakukan serta perubahan lingkungan kerja yang sudah tidak kondusif, bukan dipengaruhi oleh kinerja yang buruk. Perubahan budaya memberikan tambahan pengetahuan baru, pengalaman dan keterampilan dalam bekerja, hal ini bisa dirasakan langsung oleh karyawan. Hasil ini berbeda dengan penelitian lain yang dilakukan oleh Nurwati (2012) disebutkan bahwa perilaku kerja berpengaruh terhadap kinerja karyawan secara positif signifikan, artinya perilaku kerja karyawan yang baik berperan dalam peningkatan kinerja karyawan.

\section{Implikasi Manajerial}

Langkah awal yang bisa dilakukan karyawan adalah dengan mulai mempelajari budaya Korea Selatan dan mengenal karakter budaya tersebut yang didukung oleh manajemen dengan memberikan info-info yang berkaitan dengan budaya Indonesia-Korea Selatan di forum terbuka CMS site yang dapat diakses oleh seluruh karyawan maupun ekspatirat Korea. Selain itu diperlukan pengadaan induksi program sebagai wadah bagi ekspatriat untuk belajar budaya Indonesia yang bisa dilakukan secara praktis berupa handout dan video. Pengadaan program belajar bagi karyawan senior BWS Bogor untuk belajar bisnis korporasi di cabang korporat yang akan membantu mengedukasi karyawan BWS Bogor lainnya sehingga dapat meningkatkan kualitas sumber daya manusia BWS Bogor. Selain itu adanya migrasi sistem dari Alphabit ke WGSS, memerlukan proses pembelajaran dan praktek kerja sehingga dibutuhkan dukungan departemen IT.

Tabel 10. Hasil estimasi koefisien jalur dan uji statistik

\begin{tabular}{lccccc}
\hline Hubungan & Path & T statistik & P value & R square parsial & R square simultan \\
\hline Kejutan budaya $(\mathrm{X} 1) \rightarrow$ Perilaku karyawan (Y1) & 0,734 & 9,206 & 0,000 & - & 0,538 \\
Kejutan budaya $(\mathrm{X} 1) \rightarrow$ Kinerja karyawan (Y2) & 0,530 & 3,248 & 0,001 & 0,409 & 0,643 \\
Perilaku karyawan $(\mathrm{Y} 1) \rightarrow$ Kinerja karyawan (Y2) & 0,328 & 1,653 & 0,099 & 0,235 & \\
\hline
\end{tabular}




\section{KESIMPULAN DAN SARAN}

\section{Kesimpulan}

Kejutan budaya dinilai secara positif sebagai peningkatan pengetahuan dan keterampilan karyawan. Namun tidak sedikit karyawan yang menilai kejutan budaya secara negatif, memunculkan reaksi kecemasan dan rasa ketidakmampuan karyawan untuk bersikap dan bekerja di budaya Korea. Hal ini memengaruhi karyawan pada kawasan afektifnya yaitu kurangnya pernghargaan yang diberikan oleh perusahaan atas pencapaian usaha mereka dalam mengerjakan pekerjaan dilingkungan budaya yang baru. Sehingga memengaruhi perasaan dan menurunkan semangat serta minat terhadap pekerjaan. Kejutan budaya berpengaruh dalam peningkatan kinerja karyawan. Bekerja dalam ritme yang cepat, berhadapan dengan nasabah asing, melakukan pekerjaan diluar jobdesk dan bisa melakukan multitasking dalam bekerja dan kesempatan berkorespondensi dengan bank asing lainnya baik di dalam maupun di luar Indonesia diklaim karyawan sebagai peningkatan kompetensi dalam diri karyawan. Sehingga rekomendasi yang diberikan adalah pembelajaran dan pemahaman akan budaya Korea Selatan oleh karyawan dan budaya Indonesia oleh ekspatriat akan menciptakan lingkungan kerja yang kondusif.

\section{Saran}

Perusahaan seharusnya sudah memprediksi hambatanhambatan apa saja yang akan muncul setelah budaya Korea Selatan diterapkan, sehingga lebih fokus dalam merumuskan program pendukung untuk mengatasi permasalahan kejutan budaya. Ada baiknya dalam merumuskan program-program tersebut perusahaan melibatkan karyawan sehingga karyawan memiliki komitmen dalam menyukseskannya. Untuk penelitian berikutnya disarankan agar menggunakan peubahpeubah lain yang tidak digunakan dalam penelitian ini.

\section{DAFTAR PUSTAKA}

Adi P. 2018. Tentang Budaya Sunda. https://destinasiadi. id/2018/02/08/tentang-budaya-sunda/. [20 Jun 2019].

Ahidin U, Mutaqin A. 2014. Hubungan antara budaya organisasi dan kinerja karyawan pada PT Syaka
Putra Transindo Jakarta. Jurnal Ilmiah Prodi Manajemen Universitas Pamulang 1(2): 114135.

Andreason AW. 2003. Expatriate adjustment to foreign assignments. International Journal of Commerce and Management 13(1): 42-60.

Black JS, Gregersen HB. 1991. The other half of the picture: Antecedents of spouse cross-cultural adjustment. Journal of International Business Studies 22(3): 461-477.

Eull NA. 2005. HODI: A Comprehensive training program for employees and their partners preparing to live abroad [disertasi]. Chicago: The Chicago School of Professional Psychology.

Feng J. 2015. International adjustment in a dual cultural context: Voice of western executive expatriates in Shanghai [disertasi]. California: Fielding Graduate University.

Gibson JL, Ivancevich JM, Donnelly JH. 2001. Organisasi, perilaku, struktur, proses. Ed Ke-5. Jakarta: Penerbit Erlangga.

Gustari I. 2013. Transformasi budaya organisasi dan pengaruhnya terhadap kinerja karyawan pada bank yang diambil kepemilikannya oleh asing [disertasi]. Bogor: Institut Pertanian Bogor.

Hisam TG. 1996. The value of expatriate support programs (ESS) in reducing the susceptibility to culture shock for American expatriated employees working in Germany [disertasi]. Florida: School of Business and Entrepreneurship Nova Southeastern University.

Joseph OO, Francis K. 2015. The influence of organizational culture and market orientation on performance of microfinance institutions in Kenya. International Journal of Business and Management 10(8): 204-211.

Koesmono T. 2006. Peranan kepemimpinan dan budaya organisasi terhadap perilaku karyawan. Ekuitas 10(3): 335-348.

Latan H, Ghozali I. 2012. Partial least square konsep, teknik dan aplikasi menggunakan program smartPLS 2.0 M3. Semarang: Badan Penerbit Universitas Diponegoro.

Mansour BEl, Wood E. 2010. Cross-cultural training of European and American managers in Morocco. Journal of European Industrial Training 34(4): 318-392.

Mayangsari D, Hamid D, Prasetya A. 2014. Peranan budaya kerja Korea Selatan dalam meningkatkan kinerja karyawan studi pada karyawan PT. Cheil Jedang Indonesia. Jurnal Administrasi Bisnis. 
16(1): 1-8.

Mochklas M. 2017. Analisis gaya kepemimpinan ekspatriat Korea Selatan dalam memimpin perusahaan di Indonesia. Jurnal Eksekutif 14(2): 241-252.

Mochklas M, Fatihudin D. 2017. Analysis of organizational culture company South Korea in Indonesia. International Journal of Management 8(4): 66-74.

Morgan RP. 2015. Examining the effect of cross-cultural training to sociocultural adjustment and turnover intention of English language teacher in China [disertasi]. California: Northcentral University.

Noe RA, Hollenbeck JR, Gerhart B, Wright PM. 2010. Human Resource Management: Gaining a Competitive Advantage, 7th ed. New York: The McGraw Hill Companies, Inc.

Nurwati. 2012. Pengaruh budaya organisasi terhadap perilaku kerja dan kinerja karyawan studi pada koperasi unit desa di provinsi Sulawesi Tenggara. Jurnal Sains Manajemen 1(1): 41-51.

Oberg K. 1958. Culture Shock and the Problem of Adjustment to new Cultural Environments. Washington D.C: Foreign Service Institute.

Rodriguez SM. 2017. Quantitative study on the relationship between inter-cultural training and culture shock among American project managers working in Latin America [disertasi]. Florida: Doctor of Philosophy Capella University.

Sarwoko E. 2007. Peranan faktor individu, budaya organisasi, dan perilaku kerja terhadap kinerja karyawan radio swasta nasional di Malang. Modernisasi 3(1): 12-27.
Shi L, Wang L. 2014. The culture shock and crosscultural adaptation of Chinese expatriates in international business contexts. Journal of International Business Research 7(1): 23-33.

Sudrajat A. 2008. Taksonomi Perilaku Individu Menurut Bloom.https://akhmadsudrajat.wordpress. com/2008/01/30/taksonomi-perilaku-individu/. [28 Jun 2019].

Sujarwo A, Wahjono. 2017. Pengaruh motivasi kerja dan perilaku inovatif terhadap kinerja karyawan dengan kepuasan kerja sebagai variabel mediasi (studi kasus pada LKP ALFABANK Semarang). Infokam 1(8): 63-71.

Sulaeman MM. 1995. Ilmu Budaya Dasar: Suatu Pengantar. Bandung: PT Eresco.

Sumarwan U, Hartoyo, Fahmi I. 2018. Metode Riset Bisnis dan Konsumen. Ed Ke-4. Bogor: PT Penerbit IPB Press.

Taurisa CM, Ratnawati I. 2012. Analisis pengaruh budaya organisasi dan kepuasan kerja terhadap komitmen organisasional dalam meningkatkan kinerja karyawan (studi pada PT Sido Muncul Kaligawe Semarang. Jurnal Bisnis dan Ekonomi (JBE) 19(2):170-187.

Wardani RK, Mukzam MD, Mayowan Y. 2016. Pengaruh budaya organisasi terhadap kinerja karyawan studi pada karyawan PT Karya Indah Buana Surabaya. Jurnal Administrasi Bisnis 31(1): 58-65.

Wulandary T Syamsun M, Dirjosuparto S. 2017. Pengaruh adaptabilitas budaya organisasi dan motivasi terhadap komitmen karyawan pada organisasi PT Krakatau Steel Tbk. Jurnal Aplikasi Bisnis dan Manajemen 3(2): 196-207. 